\title{
Factors that Influence the Writing of Academic Documents
}

\author{
Raúl J. Martelo ${ }^{\# 1}$, Maira Bastidas ${ }^{\# 2}$, Natividad Villabona ${ }^{* 3}$ \\ ${ }^{\#}$ Faculty of Engineering, INGESINFO research group. University of Cartagena. \\ ${ }^{1}$ rmartelog1@unicartagena.edu.co \\ 2maira2121@gmail.com \\ ${ }^{\#}$ Faculty of Economics Sciences. University of Cartagena. \\ ${ }^{1}$ nvillabonag@unicartagena.edu.co
}

\begin{abstract}
The main factors that influence the writing of academic documents were determined, for which the Brainstorming and MICMAC techniques were applied. The study was reported as nonexperimental, cross-sectional and descriptive. 24 ninth-semester students, belonging to the Systems Engineering Program, University of Cartagena, were consulted. In the results, the students present weaknesses in the writing of documents, for aspects such as: limited lexicon, omission of important concepts, inexperience when implementing norms to quote texts from other authors.
\end{abstract}

Keyword - Blueprint, Speech, Language, Scientific Texts, Brainstorming

\section{INTRODUCTION}

Academic writing is essential to communicate ideas and results, the objective is to produce texts that share thematic, structural and stylistic characteristics [1]. In this sense, the writing of academic texts in the context of higher education, is perceived as one of the skills that must be acquired during the development of a career, and is related to the way in which students express their ideas through the discourse, using a certain genre and its linguistic characteristics [2]. Each genre is associated with the use of language, in which three elements that provide the relative stability of the genre are distinguished: theme, style and composition. In this sense, from a scientific perspective, a monograph, a scientific article, a degree work or a doctoral thesis are not the same, however, they all belong to the same genre and present similarities at the time of writing [3].

Authors such as [4], affirm that there is no technical communication, and that everyday language is used to write about science and technology. Likewise, they affirm that the only significant variation between scientific, technological and daily language is the vocabulary. On the basis of the above, students learn to produce scientific texts by having the opportunity to produce prominent genres of science, and by receiving guidance on individual characteristics and on how to make their texts come closer to the objective genre [5]. On the other hand, when growing from courses of university composition, writing programs through the curriculum and technical writing courses, the research takes as an object, the writing papers that they perform in diverse activities, particularly in those in which the writing intervenes more [6]. One of these is the document that must be written to present a thesis proposal to obtain a university degree. Document that requires a clear and precise language, but that some students do not master.

At the University of Cartagena, the students of the Systems Engineering program present difficulties when writing their preliminary project, which is a document that contains the proposed constitutive items of the thesis. These difficulties are reflected when receiving a response from the teachers in charge of evaluating this work, who mostly do not approve in the first delivery, due to the problems of writing and content. This problem has been increasing, for example, for the first period of 2017, 13 pre-projects were approved, and 10 were postponed, for a total of 23 proposals; in the second period, three were approved and 14 postponed, for a total of 17. Regarding the first period of the year 2018, only five pre-projects were approved and 19 postponed, for a total of 24. Therefore, the present research aimed to identify the main factors that influence the students of the Systems Engineering program of the University of Cartagena, at the time of writing academic documents, in order to generate strategies that allow students improve this skill.

\section{Methodology}

The present investigation is of non-experimental type, descriptive cross-sectional. In non-experimental studies, studies are carried out without deliberately manipulating the variables and the phenomena are observed in their natural environment to analyze them [7]. Likewise, based on the purpose of the investigation, a crosssectional approach is established, when data are collected in a single moment. As proposed by [8], crosssectional studies are designed to measure a phenomenon at a given time. On the other hand, the type of descriptive research only aims to collect information independently or jointly on the concepts or variables to which they refer, that is, its objective is not to indicate how the measured variables are related [9]. 


\section{A. Population and sample}

The study population was made up of the ninth-semester students enrolled in the seminar on research in the Systems Engineering program of the University of Cartagena (first academic period of 2018), which consists of a total of 24 students. Population census was used, due to the fact that the size was finite and accessible, the above based on what was presented by [10].

\section{B. Research instruments}

As a technique for collecting information, the Brainstorming technique was used through the SoftProsp platform [11], which is a web tool developed at the University of Cartagena, which allows prospective studies. The objective of using this technique was to generate a list of ideas, in this case factors that the students considered fundamental, as well as difficulties that they had at the time of writing their preliminary project, which consists of a project that is carried out for obtain the title of Systems Engineer. To apply the technique successfully, four rules are present: a) focus on quantity, b) retains criticism, c) receive unusual ideas and d) combine and improve their own ideas and those of other participants [12]. Once the data were obtained, the corresponding analysis was carried out; we counted on the collaboration of 10 experts in the writing of scientific documents, which evaluated the Direct Influence Matrix (MID).

\section{Data analysis}

For the data analysis the MICMAC technique was used, also implemented in the SoftProsp platform. This technique seeks to identify, from a list of factors, which are determinants in a system to classify them by means of a structural analysis matrix, by dependence and influence. It also provides an analysis with a vision towards the future, where it seeks to highlight the problems present in the system and identifies the functionality of its dynamics [13], through tables and graphs that facilitate the understanding of the results [14].

\section{RESULTS}

The results of the investigation are shown below, in the first instance, Figure 1 shows the results obtained from the application of the Brainstorming technique, to the study population.

\begin{tabular}{|l|l|}
\hline 1 & \multicolumn{1}{|c|}{ Factores que inciden en la redacción de fextos académicos } \\
\hline 2 & Redacción pobre y omisión de conceptos importantes \\
\hline 3 & Desconocimiento de las normas para citar textos de otros autores \\
\hline 4 & Falta de experiencia en la búsqueda de información que soporte teóricamente el tema \\
\hline 5 & Habilidad para transmitir una idea y mantener la coherencia entre párrafos \\
\hline 6 & Motivación para redactar \\
\hline 7 & Presentar la teoría necesaria sin que se redunde y expresar conceptos claras y precisos \\
\hline 8 & Desconocimiento de los diferentes tipos de investigación \\
\hline 9 & Mal uso del lenguaje \\
\hline 10 & Problemas de ortografía \\
\hline 11 & Uso inapropiado de signos de puntuación \\
\hline 12 & Uso de conectores para enlazar párrafos \\
\hline
\end{tabular}

Fig 1. Results of applying the Brainstorming technique

As shown in Figure 1, the population selected 12 factors that they considered fundamental and influential when writing their preliminary draft. Factor 1 refers to the limited capacity they present when writing a text; some expressed that they sometimes tended to repeat words and wrote in colloquial language. The factor 2 , refers to the closed wording and the omission of important concepts, students said they did not write what was necessary for the reader to understand the text, because from their perspective the meaning of some terms was obvious, however, they met readers for whom the terms were unknown. Factor 3 deals with the inexperience of how to use different standards to quote texts from other authors. Factor 4 refers to the fact that some students did not know how to search for information that theoretically supported their writing, and some argued that they could not access the information because payment was required.

In the case of factor 5 , it refers to the writing, that is, the way in which students express their ideas according to some problem, the coherence between ideas and the structuring of sentences. Factor 6 expresses the interest, the motivation, the incentive that students have when writing documents. Some express no interest in the subject, so they do not dig deep or worry about learning to write correctly. With respect to factor 7 , it refers to the presentation of the theoretical bases in a clear and precise manner. The factor 8 , represents the ignorance that 
students have about the different types of research. Some argue that this situation arises, because in the third semester they are teaching a subject in which they are trained in research, and until the ninth semester they need this subject, so they do not remember much about the subject.

The factor 9, refers to the use that is given to the language at the time of writing, some students said they used idioms, making it impossible for the reader to understand. Regarding the factor 10, some students argued that they did not have spelling problems due to lack of reading and practice in writing. The factor 11, represents the inappropriate use of punctuation marks by students, some argued that they do not identify when to use a tilde, a period or a comma. Finally the factor 12, refers to the difficulty that some students have when using the connectors to link paragraphs like: "based on", "on the contrary", "in relation to", "in relation to", among others.

When determining the main factors that the students considered as fundamental or difficulties when writing academic documents through the Brainstorming technique, we proceeded to identify which of these turn out to be determinants or keys to improve the writing and results of students in subject of preliminary project. Next, in Figure 2 the results obtained from the MICMAC matrix evaluation are presented. Which consisted in that the 10 experts in consensual form issued a value, according to the influence that a factor A has on a factor B. For the above, a value of 0 to 4 must be taken into account, where 0 means that there is no direct influence relationship; 1 means that there is a weak relationship; 2, represents a relationship of average direct influence; 3 means that there is a strong relationship and 4, represents a relationship of direct influence Potential.

\begin{tabular}{|r||r||r||r||r|r||r||r||r|r|r||r||r||}
\hline \multicolumn{10}{||c||}{ Matriz de Influencia Directa (MID) } \\
\hline \hline Var & 1 & 2 & 3 & 4 & 5 & 6 & 7 & 8 & 9 & 10 & 11 & 12 \\
\hline \hline 1 & & 3 & 1 & 1 & 3 & 3 & 2 & 1 & 3 & 3 & 3 & 2 \\
\hline \hline 2 & 3 & & 3 & 3 & 3 & 3 & 3 & 1 & 3 & 3 & 3 & 3 \\
\hline \hline 3 & 1 & 2 & & 1 & 3 & 1 & 3 & 1 & 1 & 1 & 1 & 1 \\
\hline \hline 4 & 3 & 3 & 2 & & 2 & 2 & 3 & 1 & 2 & 1 & 1 & 1 \\
\hline \hline 5 & 3 & 3 & 2 & 2 & & 3 & 3 & 1 & 3 & 2 & 2 & 3 \\
\hline \hline 6 & 3 & 3 & 3 & 2 & 1 & & 3 & 1 & 3 & 1 & 1 & 1 \\
\hline \hline 7 & 3 & 3 & 2 & 3 & 3 & 1 & & 1 & 3 & 1 & 1 & 2 \\
\hline \hline 8 & 1 & 2 & 1 & 1 & 1 & 1 & 1 & & 1 & 1 & 1 & 1 \\
\hline \hline 9 & 3 & 3 & 1 & 2 & 3 & 3 & 3 & 1 & & 3 & 3 & 3 \\
\hline \hline 10 & 2 & 1 & 3 & 1 & 1 & 1 & 1 & 1 & 2 & & 3 & 1 \\
\hline \hline 11 & 2 & 1 & 3 & 1 & 1 & 1 & 1 & 1 & 2 & 3 & & 1 \\
\hline \hline 12 & 3 & 2 & 3 & 1 & 1 & 1 & 1 & 1 & 2 & 1 & 1 & \\
\hline \hline
\end{tabular}

Fig 2. Matrix of Direct Influence

As shown in Figure 2, the experts considered that factor 1: limited lexicon maintains a strong direct influence relationship (3) with factor 2: poor writing and omission of important concepts. Likewise, they agreed that factor 1 maintains a weak direct influence relationship (1) with factor 3: Lack of knowledge of the rules for citing texts by other authors. In this way, for each factor the corresponding direct influence relationship was defined. As a result of the calculation made for the direct influence and dependency matrix, the influence plane and potential indirect dependence are shown, which reveals 6 key factors (1, 2, 5, 6, 7 and 9) in quadrant I (zone of link), 1 determining factor (4), in quadrant II (power zone), 1 autonomous factor (8), in quadrant III (autonomous area), and 4 outcome factors (3, 10, 11, and 12) in quadrant IV (exit zone), as seen in Figure 3.

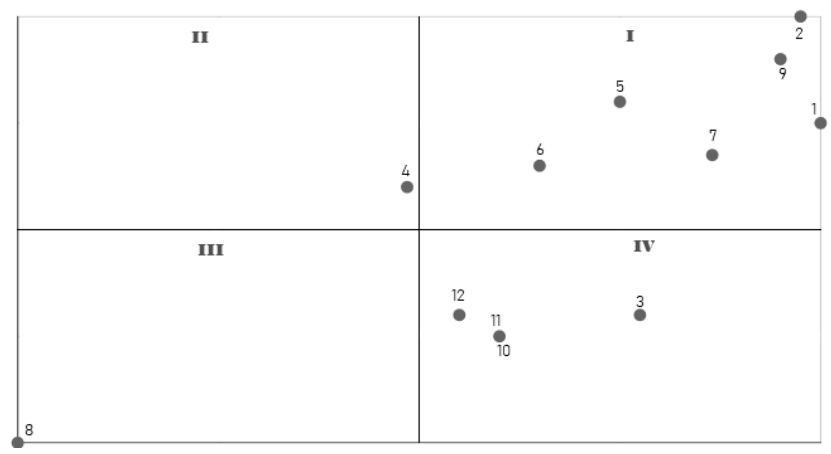

Fig 3. Plan of influence / indirect dependence

Figure 3 shows the location of the factors in the plane of influence and potential indirect dependence. The zones with the distribution of the factors are described below: 
Link zone (located in quadrant I): In this area the key factors are located, that is, factors that in the future can become critical aspects of the writing of academic texts. In this area, six factors were located: 1 (limited lexicon), 2 (poor writing and omission of important concepts), 5 (Ability to convey an idea and maintain coherence), 6 (Motivation to write), 7 (Present the theory necessary without redoing and express) and 9 (Misuse of language). These results agree with what was stated by [15], who affirms that for an efficient writing of academic texts, it must be written correctly, with a clear and direct language, and with well-structured information. A solid and appropriate structure allows content to flow, interrelate with each other, to give meaning and facilitate communication with the reader.

Similarly, [16] states that to achieve a correct wording, the paragraph should be a tool that allows, effectively, reflect what you think, use a clear, simple and concise language, using the exact word, own and adequate, correctly use punctuation marks; avoid the vices of language, take care of verbal times, avoid the use of unnecessary foreign words; should eliminate unnecessary words and phrases that do not provide any data and only delay reading. Also, [17] reports that even after years of schooling, many students have not yet mastered the grammatical and lexical characteristics that allow the presentation of a well-constructed document, even when their ideas are complex and sophisticated, the way they are presented can result in texts that do not conform to academic expectations.

On the other hand, results such as those of [18], showed that individual motivation and student interest in writing, allows the teacher to become only a resource that assists the student when necessary, that is, becomes in a facilitator instead of the source of language knowledge. Therefore, the correct management of these factors improves the writing and allows the students to present efficient academic writings with which they can obtain positive answers when writing their preliminary draft.

Power zone (quadrant II): determinant factors are located in this zone, that is, the factor that represents an input to the system and, therefore, requires attention to improve the writing of academic documents. The plan shows that factor 4 was placed in this zone (Lack of experience in the search for information that theoretically supports the subject). In this regard, [19] they report that in any episode of information search, there are variables that influence positively or negatively. In its results, it was found that variables such as: low levels of literacy, cultural norms that value the oral tradition of information transfer, negative attitudes and apathy towards information among others, intervene and play an important role.

Autonomous zone (quadrant III): in this zone is located factors that are autonomous, that is, factors that are difficult to control and therefore unpredictable. In the map it is shown that factor 8 was located in this zone (Ignorance of the different types of research). The result of this area is consistent, because the student must maintain and develop the knowledge imparted, which does not happen in this case and is a difficult aspect to handle, since it is directly related to the attitude assumed by the student in front of his career, research and writing. Likewise, these results show agreement with the findings in [20], where it was found that as the academic level increases, the use of the characteristics and teachings of the complexity of the writing also increases, for which it is essential that the student develops this ability.

Exit zone (quadrant IV): in this zone the factors that are of result are located, that is to say, factors that are a consequence of the way in which the other factors act, the results in the plan show that in this sector were located four factors: factor 3 (Ignorance of the rules for citing texts by other authors), 10 (Problems of spelling), 11 (Inappropriate use of punctuation marks) and 12 (Use of connectors to link paragraphs). These results are consistent because if the factors located in the link zone are handled correctly, then the improvements in the area will be reflected in the factors of this zone. According to [20], these improvements are also mediated by discipline and gender, which reflects the patterns observed in research on variation in professional academic writing. On the other hand, the findings of [21] showed that the writing of the student constructed in the practice of academic writing showed improvement in the knowledge, skills and the characters of the student's academic writing.

\section{CONCLUSION}

The research reveals the main factors that influence when writing academic documents through the application of Brainstorming and Micmac techniques. The results agree with a large percentage of research conducted in the same subject, which is an indication that the study was framed in real situations studied mainly by concerns that arise both locally and internationally. With the above, recommendations were generated that the students and the university, can have found so that their students better in the writing of their preliminary project. Likewise, it is concluded that the adequate management that is provided to the factors that were key, may be the solution to the problems raised in the institution studied. 


\section{REFERENCES}

[1] U.K. Simon, "Writing Popular Scientific Articles, Development of Interest in the Natural Sciences, and Non-textual Representations in Student Texts: The "Young Science Journalism" Program in Austria", In Using multimodal representations to support learning in the science classroom, pp. 11-37. Springer Cham, 2016.

[2] I. Bruce, “A role for genre-based pedagogy in academic writing instruction: an EAP perspective”, TEXT Journal, no. 21, pp. 1-215, 2013.

[3] M.M. Bakhtin, Problema rechevykh zhanrov [The problem of speech genres]. Moscow: Russkiye slovari, 1996.

[4] T. Hutchinson and A. Waters, "ESP at the cross-roads”, English for Specific Purposes Newsletter, vol. 36, pp. 1-3, 1980.

[5] J. Parkinson, "Acquiring scientific literacy through content and genre: a theme-based language course for science students", English for specific purposes, vol. 19, no. 4, pp. 369-387, 2000.

[6] D.R Russell, "Writing and genre in higher education and workplaces: A review of studies that use cultural--historical activity theory", Mind, Culture, and Activity, vol. 4, no. 4, pp. 224-237, 1997.

[7] R. Hernández, C. Fernández and P. Baptista, Metodología de la investigación. México: McGraw Hill, 2014.

[8] E. Babbie, Manual para la práctica de la investigación social. España: Desclée de Brouwer S.A., 1996.

[9] R. Hernández, C. Fernández and P. Baptista, Metodología de la investigación. México: McGraw Hill, 2006.

[10] B.C. Beins and M.A. McCarthy, Research methods and statistics. Cambridge University Press, 2017.

[11] R.J. Martelo, L. Moncaris and L. Vélez, "Integration of Regnier's Abacus, Brainstorming and Polls in the Definition of Key Variables for Prospective Studies”, Informacion Tecnologica, vol. 27, no. 5, pp. 243-250, 2016.

[12] A.F. Osborn, Applied imagination, principles and procedures of creative thinking, 1957.

[13] X.A. Arango and V.A. Cuevas, "Método de análisis estructural: matriz de impactos cruzados multiplicación aplicada a una clasificación (MICMAC)”, Doctoral dissertation, Tirant Lo Blanch, 2014.

[14] M. Godet, R. Monti, F. Meunier and F. Roubelat, La caja de herramientas de la prospectiva estratégica. Paris: Laboratoire d'Investigation Prospective et Stratégique, 2000.

[15] A.A. Berger, Media and communication research methods: An introduction to qualitative and quantitative approaches. Sage Publications, 2015.

[16] A.H. Hofmann, Escritura y comunicación científica: documentos, propuestas y presentaciones. Press - Oxford University, 2014.

[17] M.J. Schleppegrell, "Linguistic features of the language of schooling”, Linguistics and education, vol. 12, no. 4, pp. 431-459, 2001.

[18] M. Kalantzis and B. Cope, The powers of literacy (RLE Edu I): A genre approach to teaching writing. Routledge, 2014.

[19] R. Ikoja-Odongo and J. Mostert, "Information seeking behaviour: a conceptual framework", South African Journal of Libraries and Information Science, vol. 72, no. 3, pp. 145-158, 2006.

[20] S. Staples, J. Egbert, D. Biber and B. Gray, "Academic writing development at the university level: Phrasal and clausal complexity across level of study, discipline, and genre”, Written Communication, vol. 33, no. 2, pp. 149-183, 2016.

[21] F. Abdul and E. Emilia, "Facilitating Character Building through an Academic Writing Practice", Arab World English Journal, vol. 7, no 3, 2016.

\section{AUTHOR PROFILE}

Raul J. Martelo works as full-time professor at the University of Cartagena (Colombia). Mr. Martelo completed his magister from Industrial University of Santander (Colombia). Mr. Martelo completed his undergraduate in Systems Engineering at the Industrial University of Santander.

Maira Bastidas works as independent researcher at the University of Cartagena (Colombia). Mrs. Bastidas completed his undergraduate in Systems Engineering at the University of Cartagena.

Natividad Villabona works as full-time professor at the University of Cartagena (Colombia). Mrs. Villabona completed his magister from Technologic University of Bolivar (Colombia). Mrs. Villabona completed his undergraduate in Industrial Engineering at the Industrial University of Santander. 